\title{
Five Typical Emotional Reactions to Airport Security Screening: A Case Study
}

\author{
Jonathan D. Maliwat \\ WCC Aeronautical and Technological College-North Manila, Manila, Philippines
}

\begin{abstract}
For this study, there were two sets of data collection: face-to-face interview and on-line survey via "survey monkey". The survey focuses on the following: feelings associated with airport security screening and impact of awareness with prohibited items. The survey was conducted from May 13 to 31, 2018 for three weeks covering four terminals at the Ninoy Aquino International Airport (NAIA) in Manila. From the interviews and on-line survey conducted, it was evident that there are five typical emotional reactions to airport security screening processes. Forty-five percent of travelers felt frustrated upon undergoing a security screening process. On a positive note, $26 \%$ of the respondents felt relaxed and $16 \%$ have understood the screening processes being implemented in the airports. Other negative reactions surfaced were fear $(5 \%)$ and humiliation $(8 \%)$. Initial reactions and questions from departing passengers, such as "will I get trouble?" "will I be treated like a criminal or terrorist?" or "will I miss my flight", these are common responses that might be traced from a first time traveler. The results of this study will provide beneficial information to airport authorities as they determine how they can best provide a balanced-mixed of security and facilitation in managing airport security.
\end{abstract}

Keywords: Ninoy Aquino International Airport (NAIA), airport security screening, emotional reactions

\section{Introduction}

In recent years, aviation industry has been the favorite target of terrorist attacks. A case in point is the September 11 attack in the United States of America (USA) in 2001 using aircraft as a weapon to commit acts of unlawful interference. After the incident, movement of people and goods were never the same. Indeed, the September 11 incident is perhaps the most tragic and devastating terror attack in civil aviation history. The destruction of the Twin Towers caused serious damage to the economy of the USA and had a significant effect on global market. Worst of all, it has diminished consumer confidence in air transport particularly in the area of security. This was manifested with a decline in the number of travelers using aircraft as mode of transportation and to restore back consumer confidence in air transport, there is a need to review the existing level of security measures and controls in all aspect of aviation security and its effective implementation (Recomono, 2015).

\section{Annex 17 of the International Civil Aviation Organization (ICAO)}

Annex 17 of the Convention on International Civil Aviation is basic and essential regulatory regime for international aviation security because the security standards stated therein have to be implemented by every

Jonathan D. Maliwat, Bachelor of Science in Commerce, Master in Business Administration, Graduate Certificate in ASEAN Studies, Faculty Member, WCC Aeronautical and Technological College-North Manila, Manila, Philippines. 
ICAO member country. In addition, Gariepy and Botsford (1976) cited that ICAO's adjudicatory machinery plays an effective role in the settlement of disputes. It is in this context that ICAO issued several amendments to Annex 17 in order to address lapses in its implementation as manifested in the technical assessment made by ICAO. Amendment 10 is perhaps, one of the more important ICAO amendment issuances. Amendment 10 seeks to further strengthen state compliances to Annex 17. Among the more important provisions, this amendment includes the establishment of a national quality control program by the contracting state, the strict implementation of aviation security program, and information sharing between and among contracting states pertaining to aviation security related threats and best practices. It aims to restore back consumer confidence in air transport.

\section{Creation of Philippine Office for Transportation Security (OTS)}

The Philippines, in response to this global challenge, issued Executive Order (EO) 277 (Republic of the Philippines, 2004a) ${ }^{1}$ on 30 January 2004, creating the Office for Transportation Security (OTS) to secure the civil aviation system of the country. On 24 April 2004, EO 311 (Republic of the Philippines, 2004b) ${ }^{2}$ was signed, making OTS the single authority responsible for the security of all transportation system of the country, namely civil aviation, maritime infrastructure, and road and rail systems.

The government designated OTS as the lead aviation security agency under ICAO Annex 17 and developed strategic policy and national program based on ICAO recommended specifications and practices intended to both domestic and international airports in the country. Current aviation security procedures mostly focus on reducing the risk of terrorists boarding planes including the introduction of prohibited items inside the airport. Airport security management is one of the key considerations in aviation security in the aftermath of $9 / 11$. The events of $9 / 11$ forced decision-makers to examine how aviation security was being provided and how to improve it.

It bears noting, however, that since its creation in 2004, OTS was mainly focused on security screening operations of passengers and their baggage to ensure that no unlawful interference is allowed to on-board in the plane. To the general public and even for most of other government agencies, the function of OTS was not totally appreciated and fully understand by many. According to Andrade (2015), the OTS personnel were among airport workers, mostly those assigned at maintenance and security guards, who are "the heroes that the airport needs today". OTS security screening officers more often characterized as airport security personnel armed with a metal detector and occasionally conducting pat down operations, or sometimes, those sitting behind the x-ray machines, it is for this reason that OTS was then stereotyped as screeners in civil aviation sector. Current screening practices are very similar in Canada, Europe, and the United States.

In the same manner, the approval and promulgation of Department Order No. 2016-14 (Department of Transportation and Communications, Republic of the Philippines, 2016) ${ }^{3}$, transferred the airport security screening of OTS to airport authorities which also provide the impetus for the review of organizational mandate

${ }^{1}$ EO 277, approving and adopting the National Civil Aviation Security Programme, creating the Office for Transportation Security in the Department of Transportation and Communications, and reconstituting the National Council for Aviation Security as the National Civil Aviation Security Committee.

2 EO 311, designating the Office for Transportation Security as the single authority responsible for the security of the transportation systems of the country, expanding its powers and functions and for other purposes.

${ }^{3}$ Department Order 2016-14 series of 2016, the Secretary of Transportation shall have the authority and responsibility for the discharge of the powers and functions of the Department of Transportation. This Department Order shall rationalize aviation security screening responsibility between OTS and airport operators/authorities. 
and role of OTS as an attached agency to the Department of Transportation (DOTr). At present, OTS and other airport authorities continue to play a key role in aviation screening implementation.

\section{Background}

This study analyzes the passenger feelings associated with airport security screening at NAIA. From the interviews and on-line survey conducted, it was evident that there are five typical emotional reactions to airport security screening processes. The survey was conducted last May 13 to 31, 2018 for a period of three weeks at NAIA. Hence, face-to-face interview and on-line survey via "survey monkey" was used in order to capture the public's response to airport security screening process. The survey focuses on the following: feelings associated with security screening, impact of awareness with prohibited items, and other concerns with regards to airport security. Thus, there are three questions, as follows:

(1) Being a passenger, what is your first reaction to airport security and screening process being implemented in the airport?

(2) Being a passenger, are you aware of the prohibited items and regulations prescribed by the authorities including the security screening process in the airport?

(3) Being a passenger, what additional inputs or concerns you wish to share with regards to your experiences while undergoing airport security screening process.

The results of this study will provide beneficial information to airport authorities as they determine how they can best provide increased confidence about the safety and security of their airports to prospective air travelers.

\section{Methods}

The variables in this research study were air travelers. The variables have been measured by developing a survey to be delivered through email and actual face-to-face interview with the departing passengers. This study analyzes the particular feelings and reactions with regards to airport security screening. A free online survey software and a questionnaire tool are used in order to evaluate and measure the responses of the target participants. These surveys were administered in cooperation with airport authority and OTS for better participation.

\section{Literature Review}

The review of literature related to baggage screening and passenger's feelings associated in airport security will outline the rational process for baggage and pre-boarding screening of passengers. It is important to have a complete picture and analysis of the airport screening process through a review of related literatures to understand the prevailing situations and conditions that has become the standards for baggage and passenger's security screening which is being implemented in all airports around the world.

\section{Review of Literature Related to Airport Baggage Screening}

Like passenger screening, baggage screening is not a new idea. Even before 9/11, several cases of attacks to civilian aircraft with explosives placed in checked baggage had prompted authorities of several countries set up in-line screening systems. The US Federal Aviation Administration (FAA) was already committed to $100 \%$ checked baggage screening by 2010. Airport baggage handling systems are complex systems even without baggage screening. They can account for a significant portion of the cost of building and operating an airport 
passenger terminal. Most airport terminals had already expanded their baggage systems to their limits and had no space for additional equipment. The sudden need to introduce Explosive Detection Systems (EDS) quickly as required by the Aviation and Transportation Security Act (ATSA), passed by US Congress on November 19, 2001, posed an enormous challenge to airport planners (Barros \& Tomber, 2007).

The FAA requested the National Research Council (NRC) to prepare a report assessing issues concerning the implementation of new and automated passenger screening methods and barriers to their implementation. The study conducted by the Committee on Commercial Aviation Panel on Passenger Screening (1996) stated that the ideal passenger screening technology would be capable of detecting both metallic and non-metallic threat items in less than six seconds, with a high degree of accuracy including a high detection rate with a low false-alarm rate. In addition, an ideal system would give the operator enough information in an appropriate format to allow for the speedy and accurate resolutions of alarms. New screening measures at US airports are being called overly intrusive by some passengers and civil rights groups. National security experts advise using a system that relies more on intelligence, behavioral profiling, and empowering passengers (Bajoria, 2010).

Airport security procedures are tedious, stressful, and often demeaning; in 2007, a research scientist measuring the physiological stress levels of passengers at Heathrow claimed they were on a par with those experienced by fighter pilots and riot police (Richardson, 2013).

Another problem in airport security screening is queuing. Whether you are an international movie superstar, successful business-person, or Grammy winning artist, the chance to save valuable time during your international travels and bypass the millions of people that pass-through airports every day is often too good an opportunity to pass up (Complete Background Screening [CBS], 2017).

To address queuing problems, Dorton (2011) studied the utilization of discrete event simulation (DES) and queuing networks to investigate the effects of baggage volume and alarm rate at the Security Screening Checkpoint (SSCP) of a small origin and destination airport. This study utilized information from a vast body of literature and multiple subject matter experts (SMEs) to investigate important factors of SSCP. While most studies investigate staffing and equipage factors, this study investigated the effects of baggage volume and alarm rate on SSCP performance with regards to both system performance (throughput) and passenger experience (cycle time). Furthermore, this study revealed under what conditions of baggage volume and alarm rate the SSCP would be able to meet regulatory requirements as well as passenger expectations (Dorton, 2011).

\section{Review of Literature Related to Passenger's Feelings Associated with Airport Security}

As human beings, our life journey is a constant flow of experiences and emotions. Each one of us has a unique way of perceiving our surrounding world. Moreover, the circumstances around us put ourselves in a specific state of mind that influences crucially the way we interact with people, places, objects, and technology. Now, we try applying these thoughts to the air travel industry. Like other transactional and service related businesses, airports and airlines have traditionally focused on functional factors that would provide a rather rational, objective, and tangible indication of the service delivered to the passenger, thinking of waiting times, space, availability of specific services, value for money, and similar aspects (Alonso, 2017).

Lum et al. (2013) reported the findings of their field study asking more than 500 passengers at a large East Coast international airport about their experiences while going airport security. Findings indicate differences between racial groups and treatment, with nonwhites more likely to receive additional screening, have more items confiscated, feel embarrassed, and less likely to be provided an explanation for searches (Lum et al., 2013). 
Tomalin et al. (2014) are the first to examine standard and elevated-risk security measures and their influence on enplanement intentions. The results indicate that while both are similarly considered by travelers, elevated security measures introduce added concerns regarding personal privacy, and the heightened potential for humiliation; this caused the perceived dignity threat for elevated procedures to exhibit much stronger negative relationships with perceived safety and with enplanement intentions (Tomalin et al., 2014).

Kim and Park (2016) published the first airline specific research into measuring the impact of delays on passenger sentiment in July 2015. Exploring three emotional elements: anger, uncertainty, and acceptance, they looked for correlations with two key behaviours: intention to repurchase and negative word of mouth. The study looked at survey results from 365 delayed passengers, a service delay being defined as the "perceived" delay in delivering the service from the airline in question. The results were very interesting and slightly counter intuitive. They showed that a passenger's anger grew as the delay lengthened as did uncertainty but whilst uncertainty did not result in reduced intention to purchase or negative word of mouth the feeling of anger significantly reduced the intention to repurchase and showed a strong correlation with negative word of mouth. Such negative behavior has a real brand and revenue impact (Kim \& Park, 2016).

Ceccato and Masci (2017) conducted a study to report patterns of passenger's satisfaction with their safety at an international European airport. The study is based on an analysis from 2014 to 2015 passenger safety survey with particular focus on the impact of the airport's environment on passenger safety. Findings show that about one third of passengers are dissatisfied with their perceived safety. Airport entrances, security checkpoints, boarding areas, toilets, and restaurants are places where passengers declare feeling less satisfied with their safety. Regardless whether passengers are arriving or departing, their satisfaction with safety is affected by their perception of an airport's environment (e.g., elevators, overall maintenance) and also by the overall experience of being in transit (Ceccato \& Masci, 2017).

According to the statistical study conducted by the United Kingdom's Department of Transportation, in 2017 , the majority $(85 \%)$ of air passengers surveyed said they were very satisfied or satisfied with their experiences of security screening and 3\% said they were very dissatisfied or dissatisfied, remaining at a similar level to 2016. The aspects of security screening with which passengers were least satisfied were: queuing (cited by $4 \%$ ), slow speed of screening process (3\%), general organization (3\%), and staff attitude/politeness (2\%). The majority of passengers ( $80 \%$ ) said there was no aspect with which they were least satisfied. The majority of passengers (93\%) strongly agreed or agreed that any inconvenience caused by the security screening was acceptable (UK DOTr, 2018).

In summary of literatures, there have been multiples of studies related to airport baggage screening and passenger's feelings associated with airport security, while most studies focus on assessing issues concerning the implementation of passenger screening methods and others are intended to measuring the impact of delays on passenger sentiment and passenger satisfaction. But this research study is designed to highlight the emotional reactions of passengers to airport security and screening operations in Philippine settings in particular. The methods will be discussed in the following sections.

\section{Methodology}

For this study, there were two sets of data collection. First, the survey data used in this study have been gathered through face-to-face interview covering NAIA Terminal 1, 2, 3, and 4. The survey was conducted last May 13 to 31, 2018 for three weeks. The time of interviews is variable from 8 am to $5 \mathrm{pm}$ depending on the 
flights that has to be sampled. The first set of questions is about the profile of passengers (e.g., age, gender, airline, and destination). A total of 331 respondents (males and females aged 20-50) were analyzed.

Second, on-line survey via "survey monkey" was used in order to capture the public's response to airport security screening process. The survey focuses on the following: feelings associated with security screening and impact of awareness with prohibited items. Online survey shall cover the three big islands in the country from Luzon, Visayas, and Mindanao.

Total online respondents $R=185$ were achieved, consisting of:

- $R=77$ from Luzon (Laoag, Tugegarao, Clark, Manila, and Naga);

- $R=48$ from Visayas (Cebu, Bohol, Bacolod, and Iloilo);

- $R=60$ from Mindanao (Cagayan de Oro, General Santos, Zamboanga, and Davao);

- 25-50 years of age;

- $55 \%$ are male and $45 \%$ are female respondents.

\section{Results}

\section{Question 1: Being a Passenger, What Are Your Reaction to Airport Security and Screening Process Being Implemented in the Airport?}

From the interviews and on-line survey conducted, it was evident that there are five typical emotional reactions to airport security screening processes. Forty-five percent of travelers felt frustrated upon undergoing a security screening process. On a positive note, $26 \%$ of the respondents felt relaxed and $16 \%$ have understood the screening processes being implemented by OTS. Other negative reactions surfaced were fear $(5 \%)$ and humiliation (8\%).



Figure 1. A total of 331 respondents were analyzed. The survey was conducted last May 13 to 31, 2018 for three weeks covering NAIA Terminal 1, 2, 3, and 4.

\section{Question 2: Being a Passenger, Are You Aware of the Prohibited Items and Regulations Prescribed by the Authorities Including the Security Screening Process in the Airport?}

Respondents were asked to describe the experiences they had upon going through an airport screening 
process. They were also asked if they have experienced bringing in prohibited items and later surrendered to the authorities.

Online interview revealed that:

- $48 \%$ approximately half of respondents who recently passed through a security checkpoint have removed items from their pockets without being told to do so.

- $29 \%$ laptops were also removed from their bags without travelers being asked.

- $98 \%$ of passengers went through the walk-through metal detector more than once.

- $98 \%$ underwent a pat-down or frisking search.

- $59 \%$ underwent a bag search.

- $63 \%$ had to surrender a prohibited item.

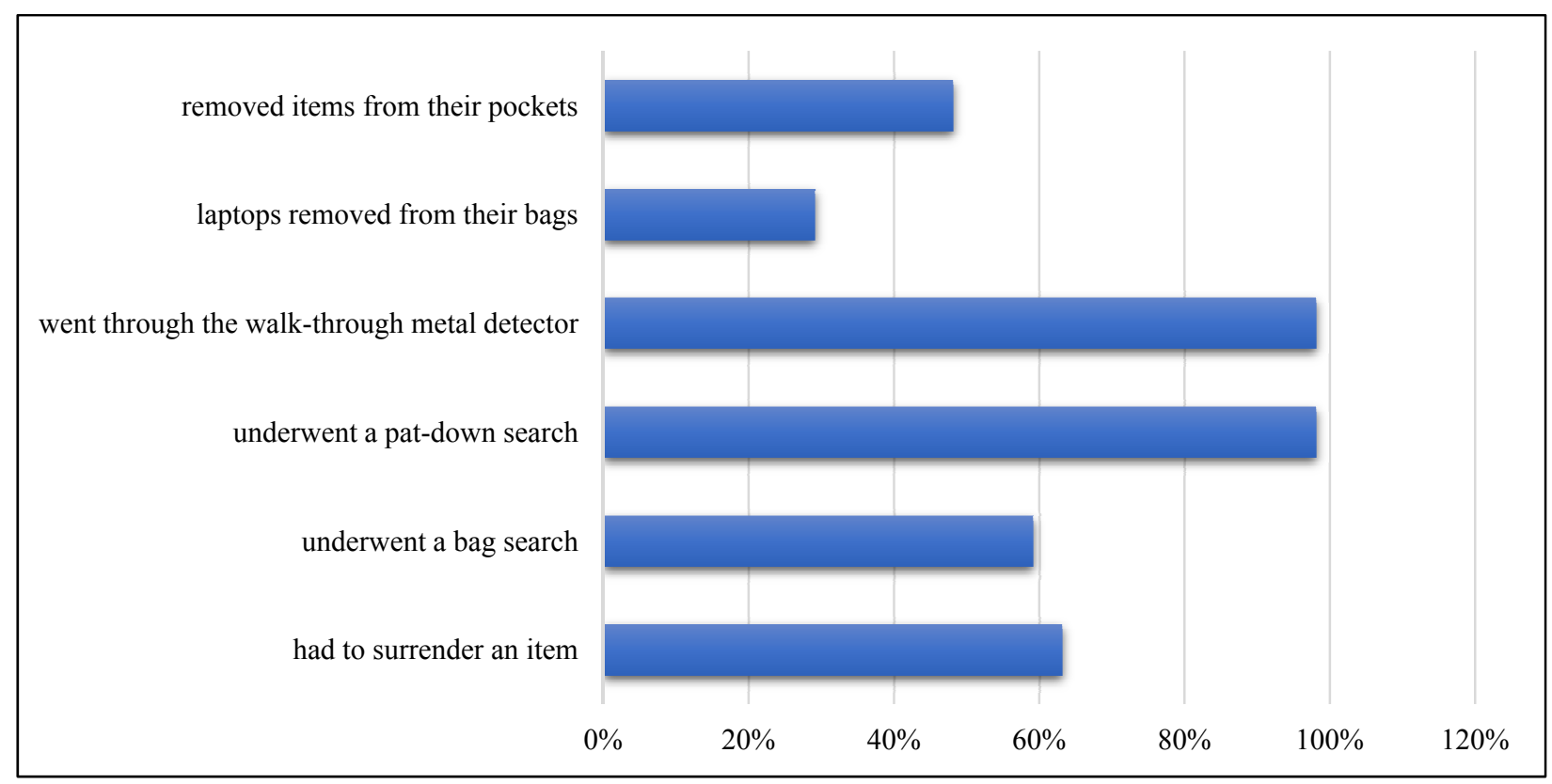

Figure 2. A total of 185 online respondents were analyzed. Online survey via "survey monkey" covers the three big islands in the country from Luzon, Visayas, and Mindanao.

\section{Question 3: Being a Passenger, What Additional Inputs or Concerns You Wish to Share With Regards to Your Experiences While Undergoing Airport Security Screening Process?}

Initial reactions and questions from departing passengers, such as "will I get trouble?" "will I be treated like a criminal or terrorist?" or will I miss my flight", these are common responses that might be traced from a first time traveler.

\section{Discussion}

From the interviews and on-line survey conducted, it was evident that there are five typical emotional reactions to airport security screening processes. Exploring five emotional elements: humiliating, frustrated, scary, welcome, and relaxed, the responses have been weighted to reflect the actual reactions and emotions passing through airport security checkpoints. Differences between airports, in terms of passenger profile should be taken into account when interpreting the results. The participants come from the main airport in Manila, so the generalizability of the sample is limited. Passenger experiences of security screening may be affected by 
changes to screening procedures, such as introduction of new technology of airport scanners. Security procedures may also be affected by passenger numbers, airport design, and the use of technology. Another challenge in managing airport security is the harmonization of security efforts of all concerned stakeholders, government, and private entities alike, involved in civil aviation security.

The management of security in airport is easier said than done. The complexities of the different facets of airport operations are indeed a tall order, both are demanding and challenging and with inclusion of a stringent security measures and controls which similarly complex and very challenging. While it is the responsibility of the airport security authority to ensure that security measures are applied consistently and effectively, we should be readily changeable in response to any increased security threat. The airport security authority should likewise be able to carry out these measures with a view to minimizing, as much as practicable, any disruptions for passengers and the public.

Finally, research similar to this should be conducted regularly to determine if the findings are partly different or similar in other airports in the country.

\section{Conclusion}

The terrorist attacks of September 11 in United States gave significant impact in air travel which revolutionized the security in the transport system worldwide. The need to regulate the security of the airports, airlines, and including air cargo through conduct of oversight functions was emphasized. It necessitated key changes in aviation security which saw stringent security regulations around the globe.

In the Philippines, two Executive Orders (EO 277 and 311) were issued in 2004, which created the OTS and designated the latter as lead regulatory agency in aviation security. During that time, OTS was mainly focused on security screening operations of passengers and cargoes in civil aviation to ensure that no security risk items are allowed into the conveyance that can be used in committing acts of unlawful interference and until such time that OTS took a critical look at its mandate through the approval and promulgation of Department Order No. 2016-14, which transferred the airport security screening of OTS to airport authorities.

The study analyzes the perceptions and reactions of air travelers to airport baggage screening and feelings associated in airport security, and how it is related to satisfaction with passenger screening experiences. The study shows that more than half (58\%) of respondents said they were dissatisfied (cited by $45 \%$ frustrated $+5 \%$ fear $+8 \%$ humiliating) and (42\%) were satisfied (cited by $26 \%$ relaxed $+16 \%$ understood the screening process). There should be a balance-mixed of security and facilitation beyond the basic security requirements. Increased security measures should be designed to counter the threat without compromising the overall smooth operations of the airport. Another challenge in managing airport security is public awareness. It is only through collaboration, coordination, and cooperation among all the stakeholders that we could able to achieve efficient security operations and thus ensure the safety and security of our airport facility and its consumers against this threat of violence. To counter this threat, it requires a holistic, risk-managed, and unified approach among all concerned stakeholders that is—-the government, industry, and the riding public—unity of effort in other words.

\section{References}

Alonso, A. G. (2017). Understanding passenger emotions: The ultimate enabler of airport excellence. Retrieved from https:/www.linkedin.com/pulse/understanding-passenger-emotions-ultimate-enabler-garc\%C3\%ADa-alonso

Andrade, J. I. (2015). 5 OTS personnel honored for acts of honesty at airport. Philippine Daily Inquirer. Retrieved from https://newsinfo.inquirer.net/728096/5-ots-personnel-honored-for-acts-of-honesty-at-airport 
Bajoria, J. (2010). The debate over airport security. Retrieved from https://www.cfr.org/backgrounder/debate-over-airport-security

Barros, A. G., \& Tomber, D. D. (2007). Quantitative analysis of passenger and baggage security screening at airports. Journal of Advanced Transportation, 41(2), 171-193.

Ceccato, V., \& Masci, S. (2017). Airport environment and passengers' satisfaction with safety. Journal of Applied Security Research, 12(3), 356-373. DOI: 10.1080/19361610.2017.1315696

Committee on Commercial Aviation Security Panel on Passenger Screening. (1996). Airline passenger security screening: New technologies and implementation issues. Retrieved from https://www.nap.edu/read/5116/chapter/1

Complete Background Screening (CBS). (2017). Airport security and screening-How the rich and famous bypass the queues. Retrieved

from https://cbscreening.co.uk/news/post/airport-security-and-screening-how-the-rich-and-famous-bypass-the-queues/

Department of Transportation and Communications, Republic of the Philippines. (2016). Department Order No. 2016-14. Retrieved from https://drive.google.com/file/d/0Bx283SS6qJi2TU5nNkNFakwtZ1E/view

Dorton, S. L. (2011). Analysis of airport security screening checkpoints using queuing networks and discrete event simulation: A theoretical and empirical approach. Retrieved from https://commons.erau.edu/edt/47

Gariepy, R. N., \& Botsford, D. L. (1976). The effectiveness of the international civil aviation organization's adjudicatory machinery. Journal of Air Law and Commerce, 42(2), 351.

Kim, N., \& Park, J. (2016). A study on the impact of airline service delays on emotional reactions and customer behaviour. Journal of Air Transport Management, 57(C), 19-25.

Lum, C., Crafton, P. Z., Parsons, R., Beech, D., Smarr, T., \& Connors, M. (2015). Discretion and fairness in airport security screening. Security Journal, 28(4), 352-373. DOI:10.1057/sj.2012.51

Recomono, R. (2015). Remarks of former OTS administrator Roland S. Recomono for the closing ceremony of airport security management course at the PNP training service. Camp Crame, Quezon City, 16 June 2015.

Republic of the Philippines. (2004a). Executive Order No. 277 . Retrieved from http://marina.gov.ph/wp-content/uploads/2018/06/eo277.pdf

Republic of the Philippines. (2004b). Executive Order No. 311. Retrieved from http://marina.gov.ph/wp-content/uploads/2018/06/eo311.pdf

Richardson, N. (2013). Airport security campaign: The high price of safety. Retrieved from https://www.telegraph.co.uk/travel/news/Airport-security-campaign-The-high-price-of-safety/

Tomalin, D. A., Ansons, T. L., Reich, T. C., Sakamoto, Y., Davie, R., Leboe-McGowan, J. P., \& Leboe-McGowan, L. C. (2014). Airport security measures and their influence on enplanement intentions: Responses from leisure travelers attending a Canadian University. Journal of Air Transport Management, 37, 60-68.

UK Department of Transportation (DOT). (2018). Air passenger experience of security screening: 2017 (Revised). Retrieved from https://www.gov.uk/government/statistics/air-passenger-experience-of-security-screening-2017 